\title{
A narrative review of acute pancreatitis and its diagnosis, pathogenetic mechanism, and management
}

\author{
Zhi Zheng ${ }^{1,2 \#} \wedge$, Yi-Xuan Ding ${ }^{1,2 \#} \wedge$, Yuan-Xu Qu ${ }^{1,2} \wedge$ Feng Cao ${ }^{1,2}$, Fei $\operatorname{Li}^{1,2} \wedge$ \\ ${ }^{1}$ Department of General Surgery, Xuan Wu Hospital, Capital Medical University, Beijing, China; ${ }^{2}$ Clinical Center for Acute Pancreatitis, Capital \\ Medical University, Beijing, China \\ Contributions: (I) Conception and design: Z Zheng, Y Ding; (II) Administrative support: All authors; (III) Provision of study materials or patients: All \\ authors; (IV) Collection and assembly of data: All authors; (V) Data analysis and interpretation: Z Zheng; (VI) Manuscript writing: All authors. (VII) \\ Final approval of the manuscript: All authors. \\ "These authors contributed equally to this work. \\ Correspondence to: Fei Li, MD, PhD. Chief Doctor, Professor, Surgeon, Department of General Surgery, Xuan Wu Hospital, Capital Medical \\ University, No. 45 Changchun Street, Xi-Cheng District, Beijing 100053, China. Email: feili36@ccmu.edu.cn.
}

\begin{abstract}
Acute pancreatitis (AP) is an inflammatory disease that can progress to severe acute pancreatitis (SAP), which increases the risk of death. AP is characterized by inappropriate activation of trypsinogen, infiltration of inflammatory cells, and destruction of secretory cells. Other contributing factors may include calcium $\left(\mathrm{Ca}^{2+}\right)$ overload, mitochondrial dysfunction, impaired autophagy, and endoplasmic reticulum (ER) stress. In addition, exosomes are also associated with pathophysiological processes of many human diseases and may play a biological role in AP. However, the pathogenic mechanism has not been fully elucidated and needs to be further explored to inform treatment. Recently, the treatment guidelines have changed; minimally invasive therapy is advocated more as the core multidisciplinary participation and "step-up" approach. The surgical procedures have gradually changed from open surgery to minimally invasive surgery that primarily includes percutaneous catheter drainage (PCD), endoscopy, small incision surgery, and video-assisted surgery. The current guidelines for the management of AP have been updated and revised in many aspects. The type of fluid to be used, the timing, volume, and speed of administration for fluid resuscitation has been controversial. In addition, the timing and role of nutritional support and prophylactic antibiotic therapy, as well as the timing of the surgical or endoscopic intervention, and the management of complications still have many uncertainties that could negatively impact the prognosis and patients' quality of life. Consequently, to inform clinicians about optimal treatment, we aimed to review recent advances in the understanding of the pathogenesis of AP and its diagnosis and management.
\end{abstract}

Keywords: Acute pancreatitis (AP); diagnostic criteria; pathogenetic mechanism; management; complications; prognosis

Submitted Jun 19, 2020. Accepted for publication Nov 26, 2020.

doi: $10.21037 /$ atm-20-4802

View this article at: http://dx.doi.org/10.21037/atm-20-4802

\footnotetext{
^ ORCID: Zhi Zheng, 0000-0003-0390-9466; Yi-Xuan Ding, 0000-0001-6752-9660; Yuan-Xu Qu, 0000-0001-6956-5665; Feng Cao, 00000001-7412-2455; Fei Li, 0000-0002-0532-9054.
} 


\section{Introduction}

In recent years, the incidence of acute pancreatitis (AP) has increased globally to approximately 34 cases per 100,000 persons annually (1). Although gallstones and alcohol consumption are the most common causes of AP, hypertriglyceridemia, drugs, endoscopic retrograde cholangiopancreatography (ERCP), trauma, obesity, diabetes, and infection are also well-known triggers of local and systemic inflammation $(2,3)$. In recent years, the treatment concept of AP has undergone considerable changes, more advocation is given to minimally invasive therapy as the core multidisciplinary participation and step-up approach (4) The surgical procedures have gradually changed from open surgery to minimally invasive surgery that mainly includes percutaneous catheter drainage (PCD), endoscopy, small incision surgery, and video-assisted surgery (4). Open surgery involves abdominal and/or retroperitoneal necrosectomy $(\mathrm{RN})$. Due to the complexity and diversity of its conditions, $\mathrm{AP}$ is no longer limited to a single treatment, as a variety of therapies have been combined and the degree and scope of necrosis, which is the so-called step-up approach. In such treatment, a multidisciplinary team is formed, focusing on surgical, endoscopic and radiological interventions and critical care medicine. Individualized treatment plans should be formulated according to the patients with specific conditions, and the step-up approach should be further applied to the treatment concept of AP to improve the cure rate and reduce the incidence of complications, so as to improve patient quality of life and long-term prognosis $(5,6)$. Owing to timely and accurate diagnosis and treatment, the population mortality and morbidity of AP have decreased over the past decade (7); nonetheless, the sequelae of AP has remained severe (8). Impaired pancreatic endocrine and/or exocrine function due to massive necrosis of pancreatic parenchymal cells is identified in approximately $20 \%$ of patients after an episode of AP (9). Moreover, chronic pancreatitis $(\mathrm{CP})$ develops in approximately $10 \%$ of patients after a first episode of AP and in about one-third of patients with recurrent $\mathrm{AP}$, with men and patients who abuse alcohol being at a specifically higher risk of transition from $\mathrm{AP}$ to CP (10). Of further clinical significance, prediabetes or diabetes mellitus develops in approximately $37 \%$ of patients after an initial episode of AP; overall, patients are at a two-fold higher risk of diabetes development over the subsequent 5 years after an episode of AP than the general population (11).

In the past decade, considerable advancements have been made in the research on the pathogenesis of AP related to the mechanism of calcium $\left(\mathrm{Ca}^{2+}\right)$ overload, trypsinogen activation, impaired autophagy and ER stress have been elucidated, which is helpful to further understand the occurrence and development process of AP. Recently, it has been found that exosomes, as transport and storage tools for proteins, nucleic acids, and lipid substances, are widely involved in the pathophysiological processes of a variety of diseases, and may play a biological regulatory role in the evolution of AP (12). Because related research remains relatively rare and the pathogenesis is not fully clear, research related to the exosomes in the pathogenesis of $\mathrm{AP}$ has become a popular research topic for scholars. Therefore, exosomes may be a new biomarker or target for the diagnosis and treatment of AP in the future. However, no effective guidelines for AP treatment exist; as such, there is a need to better understand the pathogenesis of pancreatitis to identify potential novel therapeutic targets. Hence, we aimed to review recent advances in the understanding of the pathogenesis of AP as well as its diagnosis and management to better inform treatment. We present the following article in accordance with the Narrative Review reporting checklist (available at http://dx.doi.org/10.21037/atm-20-4802).

\section{Methods}

We conducted a literature search for published manuscripts on AP up to April 2020 in PubMed, Web of Science, and EMBASE databases and employed the following search terms: "acute pancreatitis", "pancreatitis", "diagnostic criteria", "pathogenetic mechanism", "clinical management", "complication", and "prognosis". Qualitative and quantitative data were extracted by interpreting each paper in cycles to avoid missing potentially valuable data.

\section{Discussion}

\section{Diagnostic criteria and classification of AP}

The 2012 Atlanta Classification was revised to better and more accurately diagnose AP, requiring two of the following three diagnostic criteria to be fulfilled (13): (I) persistent and severe abdominal pain, often radiating to the back; (II) a threefold increase in serum lipase and/or amylase above the upper limit of the normal value; (III) and typical imaging manifestations of AP. We note, however, the limited diagnostic value of serum lipase and amylase in hyperlipidemic pancreatitis and alcoholic pancreatitis, as 


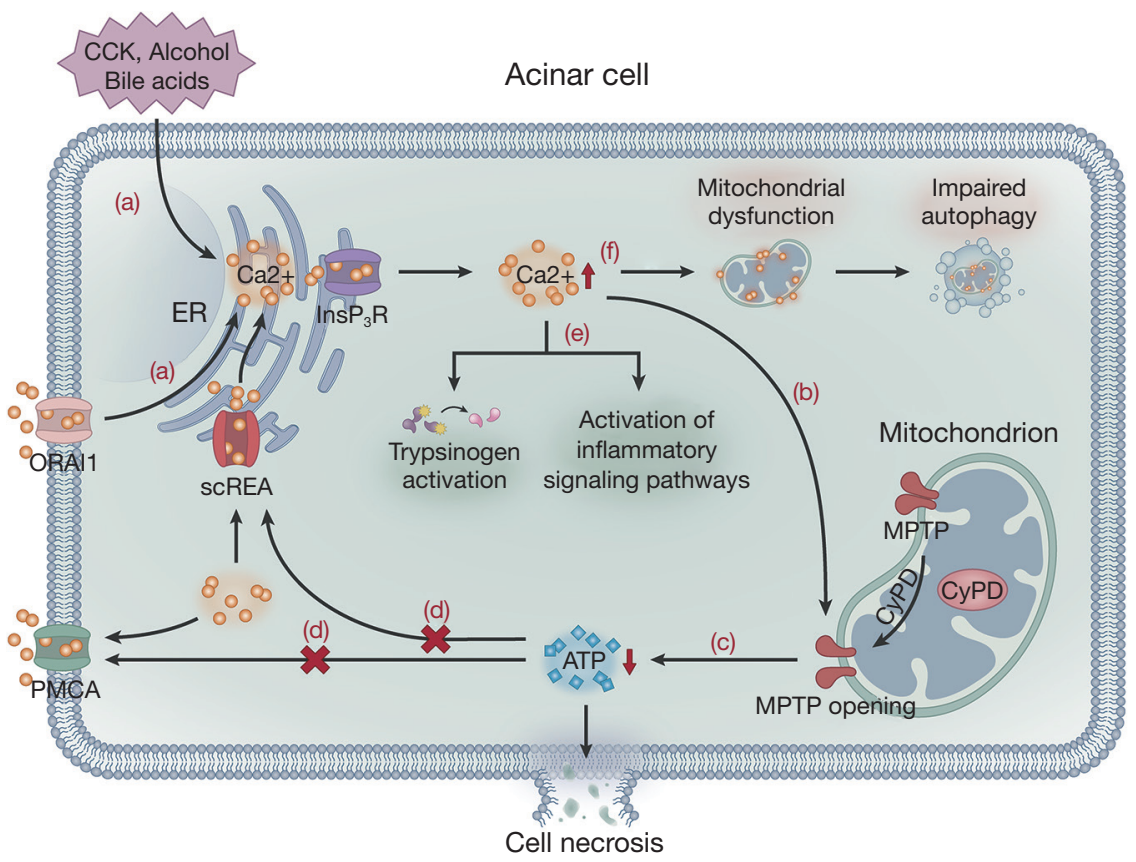

Figure 1 (a) Cholecystokinin, alcohol, and bile acids activate the ER to release stored $\mathrm{Ca}^{2+}$ via the InsP3 receptor pathway. ORAI1 promotes $\mathrm{Ca}^{2+}$ to enter the cell from the extracellular space, further increasing the $\mathrm{Ca}^{2+}$ overload. (b) Sustained $\mathrm{Ca}^{2+}$ overload increases the permeability of MPTP, which determines the sensitivity of cyclophilin D. (c) Change in the membrane potential, leading to ATP depletion and cell necrosis. (d) ATP depletion damages acinar cells by blocking SERCA and PMCA, which aggravates the intracellular $\mathrm{Ca}^{2+} \mathrm{overload}^{2}$ (e) $\mathrm{Ca}^{2+}$ overload can activate trypsinogen and inflammatory signaling pathways. (f) $\mathrm{Ca}^{2+}$ overload can also cause mitochondrial dysfunction, leading to impaired autophagy. ER, endoplasmic reticulum; $\mathrm{Ca}^{2+}$, calcium; MPTP, mitochondrial permeability transition pores; ATP, adenosine triphosphate; SERCA, smooth ER $\mathrm{Ca}^{2+}$ channels; PMCA, plasma membrane $\mathrm{Ca}^{2+}$ channels.

well as acute cholecystitis, gastrointestinal perforation, and intestinal obstruction as other causes of elevated amylase and lipase levels. Therefore, imaging is generally necessary for AP diagnosis.

An enhanced computed tomography (CT) scan is the most effective method to diagnose AP and pancreatic necrosis, with typical features on cross-section imaging including enlargement of the pancreas, pancreatic edema, uneven density, peripancreatic fat stranding, and fluid collection. Necrotizing pancreatitis should be considered when multiple "soapy" density-reducing regions of varying sizes appear in an enlarged pancreas (13). However, these features are not apparent in the early stage of AP, with evidence of pancreatic necrosis typically developing about 72 hours after onset of clinical symptoms (14). Consequently, for patients presenting with typical clinical symptoms of AP corroborated by laboratory tests, imaging may not be necessary during the first 72 hours after admission (15-17). However, if the possibility of necrotizing pancreatitis is suspected, an enhanced CT scan or CT perfusion should be performed to monitor and manage adverse outcomes on an emergent basis to prevent irreversible pancreatic necrosis and to reduce the risk of death $(18,19)$. Several scoring systems are also available to evaluate the severity of AP, including the Acute Physiology and Chronic Health Examination II score, the CT severity index (CTSI), the Harmless Acute Pancreatitis Score, and the Ranson score $(20,21)$. Of these, the CTSI has good prognostic value, with a score $<3$ being predictive of a better prognosis (22).

AP can be classified as mild acute pancreatitis (MAP), moderately severe acute pancreatitis (MSAP), and severe acute pancreatitis (SAP) (13). MAP is mainly characterized by interstitial edematous pancreatitis without organ failure and local or systemic complications. In contrast to MAP, MSAP and SAP are mainly necrotizing pancreatitis. MSAP often results in transient organ failure, lasting for $<48$ hours, with or without local or systemic complications. Local complications typically include fluid collection 
around the pancreas, formation of a pancreatic pseudocyst, and sterile or infected pancreatic necrosis (IPN) $(23,24)$, whereas systemic complications, which develop in $20 \%$ of $\mathrm{AP}$ cases, are characterized by intermittent organ failure and deterioration in disease status (25). SAP, on the other hand, is characterized by persistent organ failure, lasting for $>48$ hours, and is associated with poor prognosis and death in approximately $30 \%$ of cases $(13,26)$.

\section{Intracellular pathogenetic mechanisms of AP}

$\mathrm{AP}$ is a common disease of the digestive system, with a multifactorial pathogenesis, including $\mathrm{Ca}^{2+}$ overload, trypsinogen activation, impaired autophagy, endoplasmic reticulum (ER) stress, and exosomes. Among them, $\mathrm{Ca}^{2+}$ overload and trypsinogen activation are both equally important intracellular pathogenetic mechanisms of AP. In addition, other factors affect the development of AP, to a certain extent.

\section{$\mathrm{Ca}^{2+}$ signaling and mitochondrial dysfunction}

$\mathrm{Ca}^{2+}$ overload is a common mechanism that leads to cell damage in the body. Under a normal physiologic state, cholecystokinin activates the ER to release stored $\mathrm{Ca}^{2+}$ via the $\mathrm{InsP} 3$ receptor and ryanodine receptor pathways, with the former playing a major role in this process $(27,28)$. The resultant $\mathrm{Ca}^{2+}$ influx stimulates the mitochondria to produce adenosine triphosphate (ATP). Simultaneously, the activated secretory granules in the apex of acinar cells release protease (29). An overload of intracellular $\mathrm{Ca}^{2+}$ and mitochondrial dysfunction, triggered by cholecystokinin, alcohol consumption, and bile acids, have been shown as key steps in SAP development caused by acinar cell dysfunction $(27,30,31)$. Moreover, $\mathrm{Ca}^{2+}$ release-activated $\mathrm{Ca}^{2+}$ channel protein 1 (ORAI1) promotes extracellular $\mathrm{Ca}^{2+}$ to enter the cell, which further increases the $\mathrm{Ca}^{2+}$ overload (32). Sustained intracellular cytosolic $\mathrm{Ca}^{2+}$ overload results in mitochondrial membrane damage, increasing the permeability of mitochondrial permeability transition pores (MPTP), which determines the sensitivity of cyclophilin D and changes the membrane potential, leading to a decrease in ATP production (31,33). ATP depletion damages acinar cells by blocking the ATP-dependent smooth ER $\mathrm{Ca}^{2+}$ channels (SERCA), which transfer $\mathrm{Ca}^{2+}$ from the intracellular to the $\mathrm{ER}$, and ATP-dependent plasma membrane $\mathrm{Ca}^{2+}$ channels (PMCA), which transfer $\mathrm{Ca}^{2+}$ from the intracellular to the extracellular space $(27,34)$. This process causes dysfunction of the $\mathrm{Ca}^{2+}-\mathrm{Na}^{+}$pump on the cell membrane and the $\mathrm{Ca}^{2+}$ pump and ATP-dependent channels on the ER, which aggravates intracellular $\mathrm{Ca}^{2+}$ overload. Finally, $\mathrm{Ca}^{2+}$ overload activates intracellular and pericellular enzymes, resulting in pancreatic self-digestion (27,35). Mitochondrial dysfunction impairs cell autophagy, with a resultant production of reactive oxygen species (ROS) and cytokines, thereby aggravating pancreatic cell damage. Damaged pancreatic cells produce damage-related molecules, such as tissue factor, DNA, and heat shock protein, which activate NF-кB, MAPK, STAT3, and PI3K inflammatory signaling pathways, extending local inflammation to systemic inflammation $(36,37)$. Mitochondrial injury aggravates ER stress and lysosomal damage, as well as the release and activation of cathepsinogen and trypsinogen, leading to cytoplasmic protein degradation and cell necrosis (Figure 1) (30). Based on the study of the mechanism of $\mathrm{Ca}^{2+}$ overload, blocking $\mathrm{Ca}^{2+}$ channels to prevent AP from progressing to necrotizing pancreatitis might warrant further investigation. ORAI1 channel inhibitors can prevent extracellular $\mathrm{Ca}^{2+}$ ions from entering acinar cells and effectively relieve intracellular $\mathrm{Ca}^{2+}$ overload. Studies have shown that ORAI1 channel inhibitors can effectively prevent necrosis in AP in animal models and human acinar cells and can significantly alleviate the degree of local and systemic inflammation (38). Furthermore, MPTP inhibitors may become a potential target for AP treatment, which can effectively prevent the reduction in ATP production, maintain the transport of intracellular $\mathrm{Ca}^{2+}$ ions by ATP-dependent SERCA and PMCA channel proteins, and reduce the probability of intracellular $\mathrm{Ca}^{2+}$ overload. As a MPTP inhibitor, TRO40303 can effectively maintain the cell membrane potential and prevent necrosis in animal models of alcoholic pancreatitis and human acinar cells (39). TRO40303 is effective and well tolerated in the treatment of acute myocardial infarction and hepatitis and may be an effective way to treat AP $(40,41)$. A multicenter clinical trial is underway to evaluate the effectiveness of high-calorie parenteral nutrition $(\mathrm{PN})$ to maintain sufficient ATP consumption during AP (42).

\section{Trypsinogen activation}

Trypsinogen activation is another important, widely studied pathogenetic pathway of AP. Trypsinogen cannot be activated due to the presence of trypsin inhibitors and zymogen granule exocytosis at the apex of acinar cells (43); hence, it cannot trigger AP. Alcohol consumption, bile acids, and pancreatic toxic substances stimulate acinar cells, resulting in the increased synthesis of lysosomal and digestive enzymes in 


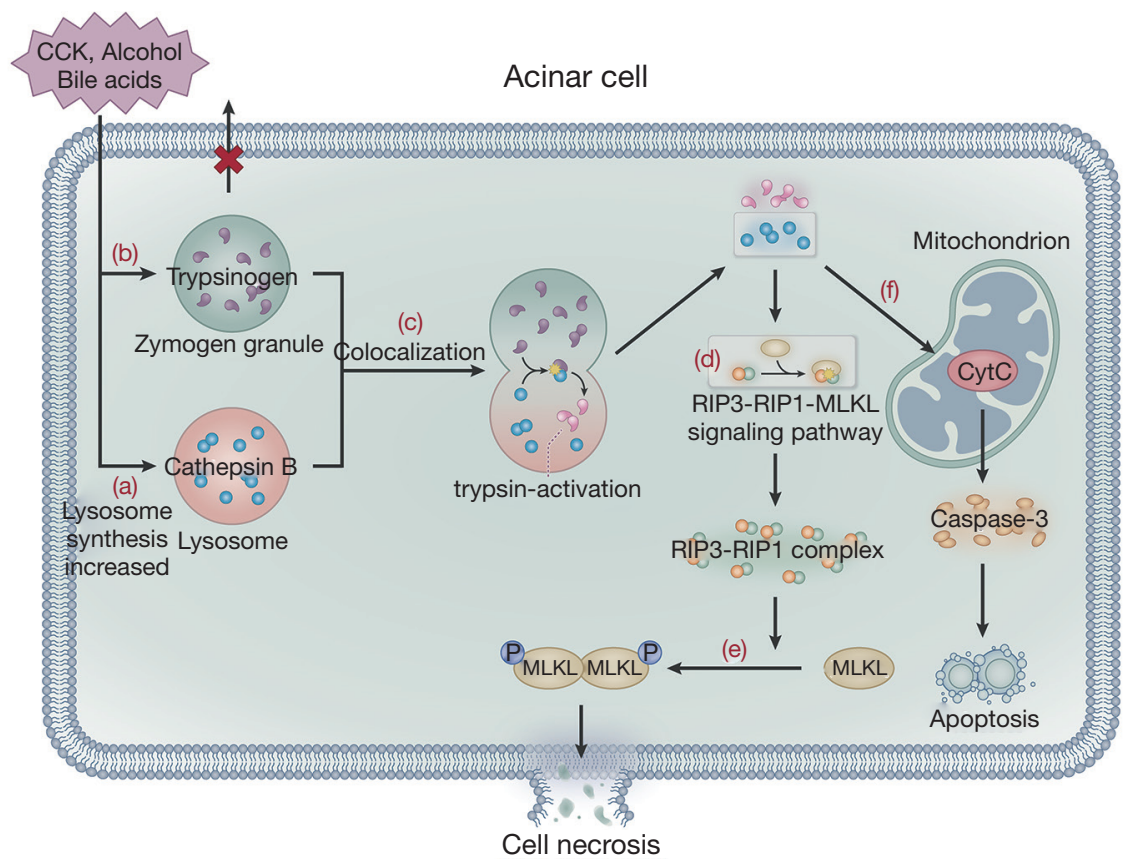

Figure 2 (a) Alcohol, bile acids, and pancreatic toxins stimulate acinar cells, increasing lysosome synthesis. (b) Pancreatic toxins inhibit the release of zymogen granules from the apex of acinar cells, which leads to an increase in the content of zymogen granules. (c) The lysosome and zymogen granules become fused, a process known as colocalization. (d) Cathepsin B causes trypsinogen activation, resulting in the release of cathepsin B and trypsin into the cytoplasm. The released cathepsin B acts on the RIP3-RIP1-MLKL signaling pathway to promote RIP3-RIP1 necrosis complex formation. (e) The RIP3-RIP1 complex acts on the MLKL, causing MLKL phosphorylation and oligomerization, which then translocates to the plasma membrane, ultimately leading to acinar cells necroptosis. (f) The cathepsin B released after lysosomal membrane rupture leads to the release of cytochrome-c from the mitochondria, which activates caspase-3 and mediates cell apoptosis.

these cells. Furthermore, pancreatic toxic substances inhibit the release of zymogen granules from the apex of acinar cells, leading to an increase in the content of lysosomal and zymogen granules in acinar cells. The lysosome and zymogen granules subsequently fuse with one another, a process known as colocalization $(43,44)$. Cathepsin B in lysosomes activates trypsinogen, causing the release of cathepsin $\mathrm{B}$ and trypsin into the cytoplasm following lysosomal membrane rupture (45). Cathepsin B in lysosomes also acts on the RIP3-RIP1-MLKL signaling pathway to promote the formation of the RIP3-RIP1 necrosis complex, which then acts downstream on MLKL protein molecules, resulting in the phosphorylation and oligomerization of MLKL protein to translocate to the plasma membrane, ultimately leading to acinar cell necroptosis (46). Blocking the RIP1-RIP3 signaling pathway by genetic modification or RIP1-specific necrosis inhibitors can alleviate the severity of acinar cell damage. Nec-1 has been used to examine the contribution of
RIP1 to inflammation in disease models (47) and can prevent heart disease and inhibit ROS production in a mouse model via downregulation of the RIP1/RIP3/MLKL signaling pathway (48). Furthermore, GSK2982772, a novel RIP1 inhibitor, actively blocks necroptosis and inflammation (49). Animal studies have shown that RIPA-56 is a target for RIP1, reducing TNF $\alpha$-mediated cell death and organ injury associated with the systemic inflammatory response syndrome (SIRS) (50) and may thus be a potential target for AP treatment $(51,52)$. On the other hand, trypsin causes self-digestion of acinar cells, with the rupture of the lysosomal membrane leading to the release of cytochrome-c from the mitochondria, which activates caspase- 3 and mediates cell apoptosis (Figure 2) (46,53). Currently, trypsinogen activation in acinar cells remains the central pathway considered to cause AP (54). However, some studies have reported that trypsinogen activation also occurs in macrophages $(55,56)$; thus, the complete pathogenetic mechanism of AP needs to 


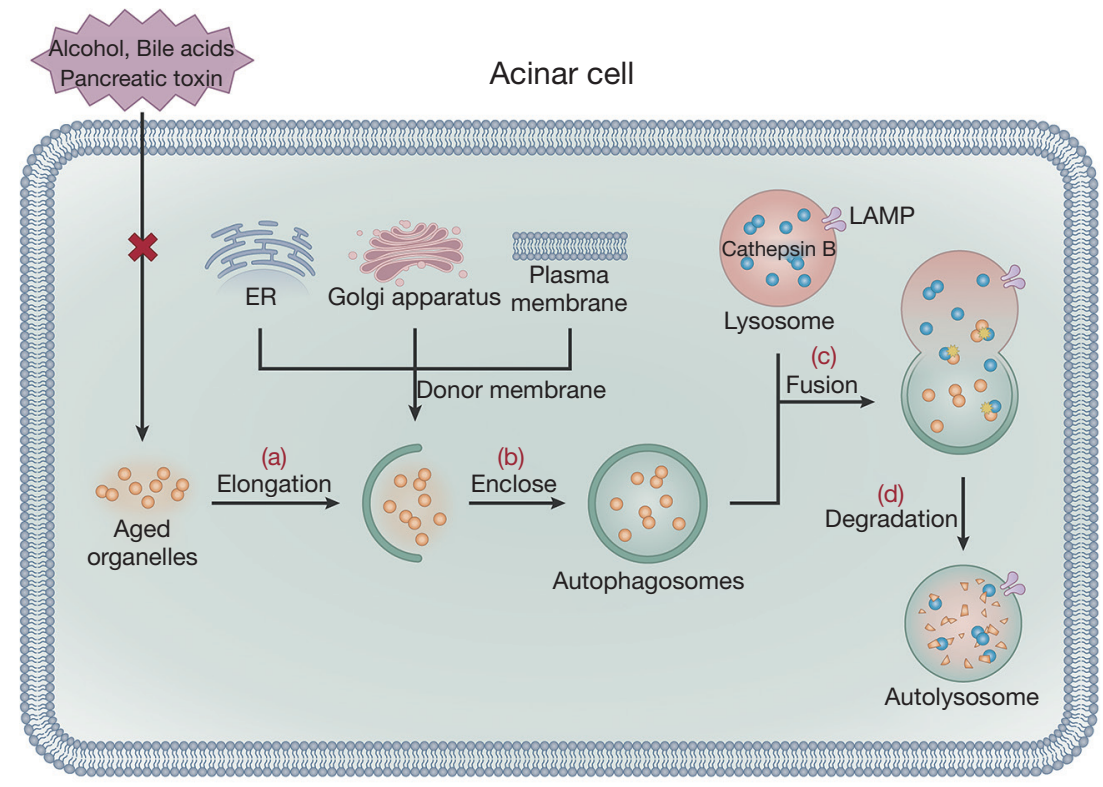

Figure 3 (a) After being stimulated by autophagy signals, cells form a circular open double membrane from the ER, with the Golgi apparatus and plasma membrane, to form an autophagy precursor. These autophagy precursors elongate aged organelles. (b) Autophagy precursors gradually enclose aged organelles to form vesicle-like structures, subsequently developing into autophagosomes. (c) The autophagosomes transfer their encapsulated contents to the lysosome cavity and subsequently fuse with lysosomes, under the mediating influence of LAMP. (d) Aged organelles are degraded by lysosome hydrolase (cathepsin B), and the degradation products are recycled in the cell. ER, endoplasmic reticulum; LAMP, lysosomal associated membrane protein.

be further investigated.

\section{Impaired autophagy}

Autophagy is a central mechanism for cell protection, allowing cells to remove damaged, aged, and nonfunctional organelles as well as denatured protein macromolecules to provide energy for cellular regeneration and recycling $(30,57)$. The process of autophagy includes four main steps (58). The first step is autophagy induction, in which cells stimulated by autophagy signals form an autophagy precursor, an open circular double membrane comprised of ER, Golgi apparatus, and plasma membrane. In the second step, mediated by the autophagy-related gene (ATG), the autophagy precursors gradually elongate and enclose damaged, aged organelles and part of the cytoplasm to form vesicle-like structures, which develop into autophagosomes. In the third step, mediated by the lysosomal associated membrane protein (LAMP), the autophagosomes transfer their encapsulated contents to the lysosome cavity where they fuse with cathepsin B to form autolysosomes. Finally, in the fourth step, after the autophagosomes are fused, they are degraded by lysosome hydrolase and the degradation products are recycled into the cell (Figure 3).

Autophagy has two functions (59). Physiological autophagy can respond to various metabolic stresses, removing unwanted or aged organelles, and, thus, providing a defense mechanism to maintain homeostasis. Excessive autophagic activity can lead to autophagy stress or defective autophagy, aggravating damage to organelles and leading to cell death. Studies have shown that physiological autophagy does not trigger the pathological process of AP (60). However, once acinar cells are activated by pancreatic toxins, alcohol consumption, and/or bile acids, the process of autophagy is impaired, promoting inflammation and cell death. Studies have shown that impaired autophagy is a prominent pathological event in AP that is associated with the abnormal activation of pancreatic enzymes $(30,61)$. Of note, a few studies have reported that the extent of autophagy vacuoles formed in acinar cells and trypsinogen activation are significantly decreased in AP mouse models with knock-out ATG5, which significantly lowers the severity of AP $(57,62)$. This research confirms that autophagy in the early stage 


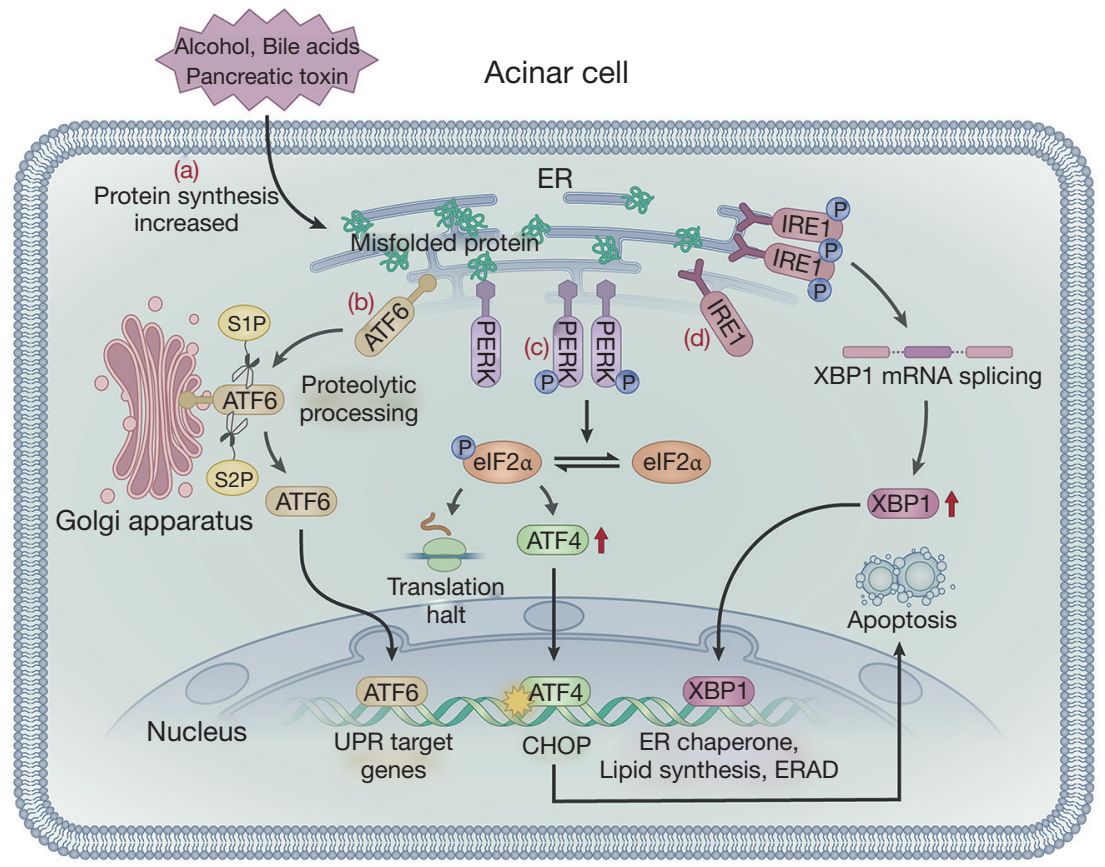

Figure 4 (a) ER stress can be triggered by alcohol, bile acids, pancreatic toxins, and increased protein synthesis. UPR is caused by an increase of misfolded or unfolded proteins in the ER. (b) ATF6 is transferred to the Golgi apparatus and is cleaved by S1P and S2P. The $\mathrm{N}$-terminal transcription activation domain is released and transferred to the nucleus as a transcription factor to promote transcription of the target gene. (c) PERK-mediated phosphorylation of eIF2 $\alpha$ shuts off mRNA translation, decreasing the protein folding load and preventing misfolded proteins from being accumulated. ATF4 upregulation can result in CHOP expression, inducing cell apoptosis. (d) When the IRE1 signaling pathway is activated, IRE1 excises a 26 nucleotide intron to form the XBP1s. The protein encoded by the XBP1 is rapidly degraded (ERAD), relieving ER stress. ER, endoplasmic reticulum; UPR, unfolded protein response; ATF, activating transcription factor; PERK, PRK-like ER kinase.

of AP activates trypsinogen, which aggravates AP disease progression $(57,62)$. Consequently, clarification of the process of impaired autophagy early in AP could provide a new target for clinical exploration for novel AP drugs. Oxidative stress is also increased due to bacterial translocation, which further aggravates AP-associated lung injury, this process may be related to decreased autophagy level (63). The AP models of IL-22 transgenic mice and IL-22 recombinant adenovirus mice induced by caerulein confirmed that IL-22 can prevent the formation of autophagosomes through the Beclin-1 pathway, thereby reducing the severity of AP (64). Additionally, impaired autophagy leads to trypsinogen activation, ER stress, and mitochondrial dysfunction, which eventually leads to acinar cell damage and death. Therefore, how AP can restore acinar cell autophagy is an important topic for future research. Furthermore, previous studies have reported that trehalose can reduce the severity of pancreatic injury in AP animal models, which may be related to increased autophagy levels; nonetheless, the specific protective mechanism is still unclear (65).

\section{ER stress}

ER stress can be triggered by hypoxia, alcohol consumption, $\mathrm{Ca}^{2+}$ overload, and oxidative stress and results in impaired post-translational modification and increased protein synthesis (66). As pancreatic acinar cells have abundant ER, the pancreas is specifically vulnerable to ER stress $(67,68)$. Basic cell biology studies have shown that ER over-activation may be an important mechanism that triggers and exacerbates pancreatic injury (69). ER stress is caused by an increase in unfolded or misfolded proteins in the ER. The stress signal is transmitted to the nucleus via the ER membrane, which in turn causes a series of specific target transcription and protein translation levels to 


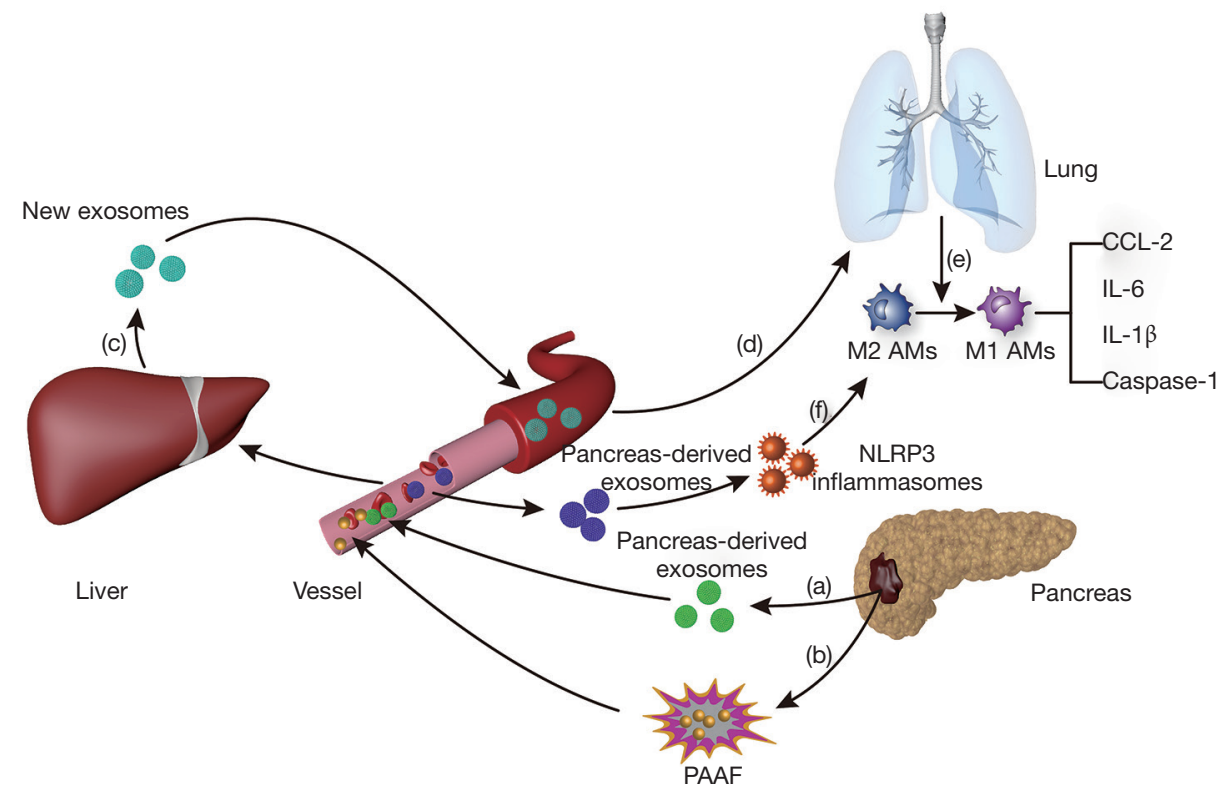

Figure 5 (a) During the AP, the pancreas can release the exosomes to peripheral blood, some of exosomes (green circle) can reach the liver via the portal system and can be retained in the liver tissue. (b) The remaining part of the exosomes (yellow circle) can be degraded by the high hydrolytic activity of the PAAF and then is transferred to the hepatic tissue (c) The liver generates and releases the new exosomes (blue circle) to the circulatory system. (d) The new exosomes (blue circle) reach alveolar tissues and are absorbed by AMs. (e) Exosomes from the circulatory system (blue circle) of the AP model activate AMs cells by converting the phenotype from M2 to M1, which in turn aggravate the degree of lung injury. (f) Plasma-derived exosomes (purple circle) activate NLRP3 inflammasomes to induce pyrolysis of alveolar macrophages, thereby causing AP-related lung injury. AP, acute pancreatitis; PAAF, pancreatitis-associated ascitic fluid; AM, alveolar macrophage; NLRP3, NOD-like receptor protein 3.

be downregulated, allowing the cell to survive, known as the unfolded protein response (UPR). In the early stage of ER stress in acinar cells, the UPR is activated to restore ER homeostasis and allow cell survival (70). UPR is regulated by three ER transmembrane proteins: inositol-requiring enzyme $1 \alpha$ (IRE1 $\alpha$ ), PRK-like ER kinase (PERK), and activating transcription factor 6 (ATF6) (71). When unfolded proteins accumulate in the ER, BiP/GRP78 dissociates with three transmembrane proteins and binds to unfolded proteins, thereby activating the UPR signaling pathways (72). PERK can be activated by self-dimerization and phosphorylation of the cytoplasmic domain, which promotes eukaryotic translation initiation factor- $2 \alpha$ (eIF $2 \alpha)$ phosphorylation. This process can rapidly reduce the initiation of mRNA translation, slow or suspend protein synthesis, and reduce the pressure on the ER to fold newly synthesized proteins. This is important as upregulation of ATF4 can increase the transcription of factor $\mathrm{C} / \mathrm{EBP}$ homologous protein (CHOP), which induces cell apoptosis. PERK-mediated phosphorylation of eIF $2 \alpha$ may shut off mRNA translation, decreasing the protein folding load on the ER and preventing accumulation of misfolded proteins and, thus, CHOP-induced cell apoptosis (73). ATF6 is transferred to the Golgi apparatus and is cleaved by site-1 (S1P) and site-2 (S2P) proteases. The $\mathrm{N}$-terminal transcription activation domain is released and transferred to the nucleus as a transcription factor to promote the expression of the ER molecular chaperones XBP1 and CHOP $(71,74)$. ATF6 can increase the protein folding capacity of the ER. When the IRE1 signaling pathway is activated, the IRE1, in two specific positions, excises a 26 nucleotides intron of unspliced X-box binding protein 1 (XBP-1) mRNA to form the spliced XBP-1 mRNA (XBP1s). The protein encoded by the XBP1 is rapidly degraded, relieving ER stress $(71,72)$. UPR is a sophisticated signaling network, which can activate the PERK, ATF6, and IRE1 signaling pathways that block protein translation and synthesis. Meanwhile, the UPR pathway can also increase protein folding and increase the degradation of misfolded proteins, 
both of which relieve ER stress (Figure 4). When the ER disorder exceeds the regulatory capacity of the cell, ER homeostasis cannot be restored and the resultant prolongation in ER stress causes inflammation and cell death or apoptosis (75). The occurrence and development of AP are closely related to ER stress $(67,69)$. UPR activates the NF- $\mathrm{KB}$ inflammatory pathway through three signaling pathways, leading to progressive exacerbation of acinar cell inflammation and cell necrosis. The process eventually leads to AP exacerbation. Therefore, NF- $\kappa \mathrm{B}$ inhibitors (IL-10 and cAMP) can block ER stress, down-regulate pro-inflammatory factors, such as TNF- $\alpha$, IL-1 and IL-6, and delay the progress of inflammation (76). Meanwhile, several studies have demonstrated that peroxisome proliferator activator receptor gamma (PPAR- $\gamma$ ) ligand, pyrrolidine dithiocarbamate (PDTC), proteasome inhibitor, and calpain I inhibitor have inhibitory effects on NF- $\mathrm{NB}$ activation in experimental AP (77). Another study revealed that 4-phenylbutyric acid (4-PBA) can inhibit the activation of trypsinogen and UPR, thus alleviating the pro-apoptotic pathways associated with ER stress and reducing systemic inflammation and cell apoptosis (78). In an observational study, HMG-CoA reductase inhibitors were found to promote UPR, with long-term use of statins reducing the severity of AP. Therefore, HMG-CoA reductase inhibitors help prevent the recurrence of AP (79).

\section{Exosomes and AP}

Exosomes are vesicles secreted by various living cells, including RNA and proteins (30-100 $\mathrm{nm}$ in size). Considering the significant increase in exosomes in the peripheral blood of patients with AP, exosomes may play an important regulatory role in the progression of pancreatitis, which has now become a popular topic of research. In the AP model of rats, the content of the exosomes, which is released to the peripheral blood by the pancreas, was significantly increased. Some of the contents of the exosomes can directly reach the liver through the portal system and can be retained in the liver tissue, while the remaining contents of the exosomes can be degraded by the high hydrolytic activity of pancreatitis-associated ascitic fluid (PAAF) and then transferred to the hepatic tissue. Subsequently, the liver may generate and release new exosomes. When the exosomes labeled with fluorescent dye were observed, it was found that exosomes from the circulatory system could effectively reach alveolar tissues and be absorbed by alveolar macrophages. Exosomes from the circulatory system of the AP model can activate alveolar macrophages cells by converting the phenotype from M2 to M1, which in turn aggravate the degree of lung injury caused by AP (80). Meanwhile, another study found that plasma-derived exosomes can activate NOD-like receptor protein 3 (NLRP3) inflammasomes to induce pyrolysis of alveolar macrophages, thereby causing AP-related lung injury. On the contrary, inhibition of exosome release or uptake by inhibitors can suppress the pyroptosis of alveolar macrophages cells, thereby reducing the extent of AP-induced lung injury (81) (Figure 5). In addition, abundant exosomes visible in the culture medium of acinar cells during AP may be a vital condition for the activation of macrophages. Analysis of microRNA (miRNA) and target genes in exosomes confirmed that acinar cells activate macrophages mainly through the MAPK pathway in AP, which contributes to acinar cell injury via apoptosis, necrosis, and autophagy (82). These findings are of great importance in support of research on exosome-miRNA in AP. Exosomes can activate the CaN/NFAT signaling pathway via miRNA-23a, activating the transcription of various chemical factors and ATGs. This causes trypsinogen to be excessively secreted in interstitial tissues, causing local inflammation that can expand to a systemic inflammation response (83). In addition, exosome-miRNA can transfer to other organs, such as the lungs, kidney, and intestinal tract, via the circulatory system. Once activated by exosomes-miRNA, these organs begin to release new exosomes, promoting cell apoptosis and organ injury $(84,85)$. However, exosomes derived from different cells may play different roles in the pathogenesis of AP. For example, exosomes derived from bone marrow mesenchymal stem cells (MSCs) have a healing effect on AP (86). In addition, exosomes-miR-223-3p from MSCs can also attenuate cerebral injury via inhibiting M1 polarization mediated pro-inflammatory response, which may be related with a negative effect on exosomes-miR-223-3p for CysLT $_{2} \mathrm{R}$ (87). Therefore, there is a need to further investigate the similarity and specificity of exosomes in different cells, tissues, and organs, the targeting mechanism of exosomes, as well as the gene regulation mechanism of target organs. As exosomes can protect RNA or protein from being damaged, it may be a promising treatment in the future (12). Hence, drug trials focusing on exosome-related targets could improve the success rate of AP treatment.

\section{Management of AP}

\section{Fluid resuscitation}

Several types of fluids are currently used for fluid 
resuscitation, which mainly include crystalloid and colloidal solutions. An increased risk of mortality and kidney failure requiring renal replacement therapy has been observed when using hydroxyethyl starch instead of crystalloid solution $(88,89)$. At present, the use of crystal fluids for fluid resuscitation is generally preferred, with colloidal fluids playing an auxiliary role $(90,91)$. Wu et al. (92) compared lactated Ringer's solution to normal saline with respect to $\mathrm{C}$-reactive protein (CRP) levels after a 24-hour infusion. CRP levels were lower with the lactated Ringer's solution $(51.5 \mathrm{mg} / \mathrm{dL})$ than with the normal saline solution $(104 \mathrm{mg} / \mathrm{dL})(\mathrm{P}=0.02)$. Moreover, the systemic inflammatory response improved to a greater extent in patients treated with Ringer's solution (84\%) than in those treated with normal saline $(0 \%)$ solution $(\mathrm{P}=0.035)$ (92). Of note, previous research has also reported a higher rate of morbidity and mortality when using saline compared to other crystalloid fluids for the treatment of SIRS $(93,94)$. A large amount of normal saline intake can cause perchloric acid poisoning, which is associated with an increased probability of kidney injury. In this sense, Ringer's solution provides an advantage over normal saline in terms of acid-base metabolism balance (95). Therefore, the IPA/APA guideline suggests that lactated Ringer's solution is superior to normal saline for AP treatment (17). However, this suggestion is based on limited evidence from small-sample randomized controlled trials (RCTs); hence, further research on fluid resuscitation for AP is required (96), including large-sample, multicenter RCTs.

Pancreatitis increases the demand for fluids, with the volume of fluid replacement needed determined based on clinical disease status and the principle of balancing the intake and output fluid volume. Insufficient or slow fluid replacement will adversely affect organ function and inflammation control (97), prolonging the duration of hospitalization. However, a RCT from China is important in this regard, having found that, compared to relatively slow hemodilution (hematocrit $\geq 35 \%$ ), rapid hemodilution (hematocrit $<35 \%$ ) is associated with a higher incidence of sepsis and mortality within 48 hours of hospitalization (98). Another study compared two rates of fluid infusion (10-15 vs. $5-10 \mathrm{~mL} / \mathrm{kg} / \mathrm{h}$ ) among patients with $\mathrm{SAP}$, with the higher rate $(10-15 \mathrm{~mL} / \mathrm{kg} / \mathrm{h})$ having been shown to be associated with a higher incidence of infectious complications and mortality (99). Based on available evidence, the American Gastroenterological Association (AGA) suggested that early goal-directed fluid therapy is important for the management of AP, being cognizant of the potential harm of blindly pursuing rapid and massive fluid resuscitation (15). Although both the ProCESS and ARISE trials showed that early goal-directed fluid therapy has no effect on the long-term mortality of patients (28 vs. 90 days), it can reduce short-term mortality and still has significance for the treatment of patients with SAP (100-102).

In addition to the issues noted above, there is a need to monitor clinical indicators to determine if treatment goals have been reached. Non-invasive indicators can be used in most cases to monitor whether fluid resuscitation goals have been achieved, including an increase in the mean arterial pressure to $65-85 \mathrm{mmHg}$, a heart rate $<120$ beats/min, and urine volume $>0.5-1 \mathrm{~mL} / \mathrm{kg} \cdot \mathrm{h}$ (17). Invasive indicators such as central venous pressure and cardiac output can be used to assess the effects of fluid infusion (103). Several other parameters can be utilized to evaluate the effects of fluid infusion, including BUN, hematocrit, and serum creatinine. Previous studies have reported that a hematocrit level $<44-47 \%$ and an increase in BUN were predictive of pancreatic necrosis $(92,104)$. The above-mentioned indicators need to be comprehensively evaluated together to avoid misjudgment of the clinical diagnosis, which can lead to serious adverse consequences.

\section{Use of analgesics}

Pain is the main symptom of AP, requiring appropriate analgesic treatment (105). Several types of analgesics can be used, including non-steroidal anti-inflammatory drugs, fentanyl, and meperidine. Basic research using an animal model indicated that morphine might have an adverse effect on pancreatitis, causing spasm of the Oddi sphincter, which aggravates the disease status (106). Of note, however, a Cochrane review did not find that opioids caused serious complications (107). A meta-analysis revealed similar outcomes, with no evidence of a negative effect of using morphine for pain control in AP (108). As current evidence is unclear, the use of morphine should be avoided for the control of pain in AP, with high-quality multicenter RCTs being required to clarify this issue. Considering the addictive effect of opioids, non-steroidal anti-inflammatory drugs can be selected as the first line pain management for AP without acute kidney injury and peptic ulcer (109).

\section{Nutritional support}

Patients with MAP only need short-term fasting without additional nutritional support. Nevertheless, nutritional support is an important component of comprehensive SAP treatment and provides sufficient caloric intake, 
which can improve the clinical prognosis to some extent $(110,111)$. Patients with SAP are in a state of high catabolic metabolism, resulting in a large consumption of protein and glycogen. If nutrition is not adequately supplemented in a timely fashion, it may lead to malnutrition and an immunocompromised state. Lack of enteral nutrition (EN) has been proven not only to change the composition of the intestinal epithelial barrier function, but to cause bacterial translocation, and promote the occurrence of infectious complications such as pancreatic infection and peripancreatic necrosis, which aggravates the patient's systemic inflammatory response to a certain extent. Therefore, active and effective nutritional support is of vital importance for maintaining and improving the nutritional status of AP patients, maintaining intestinal barrier function, inhibiting bacterial translocation, and reducing systemic inflammatory response $(3,112,113)$.

Compared to $\mathrm{PN}, \mathrm{EN}$ or oral intake does not increase the risk of adverse events and may shorten the length of hospital stay in patients with AP $(114,115)$. A review of 18 RCTs comparing EN to $\mathrm{PN}$ provides evidence that $\mathrm{EN}$ confers a benefit in reducing the rate of complications associated with infection and the length of stay in an intensive care unit, but did not have an effect on overall mortality (116). Other studies reported a superiority of EN over PN or delayed EN in reducing the rate of complications due to severe pancreatitis infection $(117,118)$. However, it is important to note that research evidence is not consistent with regard to $\mathrm{EN}$, with two studies reporting that EN did not reduce the risk of mortality and infectious complications compared to PN $(119,120)$. This difference may be because that the patients enrolled in the above two studies were all SAP combined with septic shock, and the systemic inflammatory response was severe. Therefore, early EN support could not effectively reduce the occurrence of infectious complications and suppression of systemic inflammatory response. Overall, further research is warranted to determine the benefit, if any, of EN over PN.

Meanwhile, the optimal timing of early nutritional support for $\mathrm{AP}$ also remains controversial. Wu et al. (121) reported an incidence of organ failure in $81 \%$ of patients with AP in whom EN was delayed, compared to a rate of $21 \%$ among patients provided with early EN. A meta-analysis comparing delayed $\mathrm{EN}$ or PN ( $>24$ hours) with early EN ( $<24$ hours) decreased the rate of multi-organ failure and pancreatic-related infections among patients with $\operatorname{SAP}(118,122)$. A review of three meta-analyses indicated that, compared to delayed $\mathrm{EN}$ or $\mathrm{PN}$, early $\mathrm{EN}$ ( $<24$ hours) significantly reduced the rate of mortality, surgical intervention, multi-organ failure, and SIRS among patients with AP (123-125). In summary, compared to delayed $\mathrm{EN}$ or PN, EN provided within the first 24 hours of AP may be of benefit (15).

EN can be provided via a nasogastric or a nasojejunal tube. The first RCT regarding the effects of EN route was conducted in 2005 , with findings indicating that there is no difference between nasogastric and nasojejunal feeding with regard to mortality, tolerance to $\mathrm{EN}$, and length of hospital stay (126). Several studies reported similar outcomes, including no difference in the rate of infectious complications, gastrointestinal discomfort, and the need for energy supplementation between the two routes of EN feeding (127-129). Therefore, both nasogastric and nasojejunal feeding are feasible for EN in patients with the AP. However, the above research does not solve the problem of safety (130). Generally, nasojejunal feeding would be useful for patients at high risk of aspiration, with nasogastric feeding useful for patient with a low risk of aspiration (15).

Although clinical benefits of EN have been shown, oral feeding (OF) retains several advantages over EN, such as avoiding the pressure of a nutrient tube on the nasopharyngeal and esophageal mucosa, as well as discomfort and diarrhea caused by tube feeding (131). Consequently, several studies have compared EN to OF. A meta-analysis of five RCTs showed that early OF (within 24 hours) can shorten the length of hospital stay, while avoiding abdominal pain and bloating (132). Two RCTs also reported that most patients can tolerate OF without increased risk of complication, infection rate, and mortality $(133,134)$. Based on this evidence, AGA recommends initiation of early OF instead of EN (15).

\section{Antibiotic prophylaxis}

The academic community has continued to debate the utility of antibiotic prophylaxis in the management of AP (7). Two decades ago, antibiotic prophylaxis was recognized as an important component of the clinical management of AP (7). Since then, multicenter prospective RCTs and meta-analyses have shown that prophylactic antibiotic is ineffective to prevent infections and does not lower the rate of complications and mortality among patients with SAP $(135,136)$. Nakaharai et al. (137) reported that routine use of prophylactic antibiotics might, in fact, increase the risk of hospital-acquired infections, rather than being of any benefit to patients with AP. Consequently, guidelines for AP treatment indicate that intravenous antibiotics are not recommended for the prevention of infections among patients with AP $(15,17)$. However, patients with AP clearly 
accompanied by an infection, infection-related shock, organ dysfunction, and systematic inflammatory response need to be treated with antibiotics $(17,138,139)$.

\section{Etiological treatment Acute biliary pancreatitis}

The optimal timing and method for the treatment of biliary stones in patients with acute biliary pancreatitis remain controversial $(140,141)$. For patients with MAP, laparoscopic cholecystectomy is recommended during the initial period of hospitalization (142) and may shorten the length of hospital stay and decrease the risk of gallstone recurrence, without an increased risk of conversion to open cholecystectomy, complication, or increase in procedural time (143-145). Therefore, laparoscopic cholecystectomy should not be delayed for 2 or more weeks $(144,146)$. ERCP should be performed urgently (i.e., within 24 hours) for SAP associated with acute cholangitis, as a delay is associated with an increased risk of mortality $(16,17,147-149)$. However, for patients with an inflammatory response, delaying cholecystectomy for $\geq 6$ weeks is recommended until regression of the inflammatory response is achieved $(110,150)$. For elderly patients who cannot tolerate surgery, endoscopic sphincterotomy (EST) provides a temporary option to ERCP and can decrease the risk of biliary pancreatitis recurrence $(151,152)$. Definitive cholecystectomy can be performed once the patient's physical condition has improved (153). However, EST does carry the risk of introducing bacteria into an otherwise sterile pancreatic necrosis, as well as increasing the risk of other complications. As such, the pros and cons of EST need to be weighed on a patient-by-patient basis.

\section{Hyperlipidemic AP (HLAP)}

A key point in the treatment of HLAP is the rapid reduction in the blood triglyceride (TG) level to $<5.65 \mathrm{mmol} / \mathrm{L}$ to alleviate disease progression, with possible treatment including plasmapheresis and anti-hyperlipidemic drugs, often in combination with the clinical use of heparin and/or insulin, as needed $(152,154)$. For mild HLAP, fasting and routine treatment can significantly reduce blood lipids and achieve clinical cure. However, for severe HLAP, routine treatments cannot reduce blood lipids to the normal level or the level of blood lipid decline is very slow, requiring plasmapheresis. Several studies have reported that plasmapheresis can effectively decrease serum TG, remove inflammatory lipoproteins, and shorten the length of hospital stay $(155,156)$. Furthermore, the long-term use of anti-hyperlipidemic drugs in combination with lifestyle and dietary changes is a key component of HLAP management (157). Additionally, administration of heparin or insulin can reduce the TG level within a short time, accelerate the hydrolysis of chylomicron and TG, and achieve the purpose of reducing TG. Heparin or insulin administration can also control the patient's blood sugar and improve the local blood circulation of the pancreas. He et al. (158) reported that treatment using low-molecular-weight heparin and insulin provides a better outcome, at a lower healthcare cost, than early high-volume hemofiltration. Serum TG levels should be monitored after discharge in these patients to prevent recurrence $(159,160)$.

\section{Complications}

\section{Acute fluid collection (AFC)}

AFC occurs in the early phase of AP ( $<4$ weeks), located inside and/or around the pancreas, without a cystic wall, which can be diagnosed by imaging (161). In most cases, $\mathrm{AFC}$ is sterile and is naturally reabsorbed without surgical intervention.

\section{Symptomatic pseudocysts}

When AFC persists beyond 4 weeks, there is the possibility of surrounding fibrous tissue forming a pseudocyst, with a round or ellipse shape; enlargement of the cyst may cause symptoms of compression, while infection of the cyst can induce an inflammatory response (162). For a pancreatic pseudocyst with an immature cystic wall, conservative therapy is generally recommended, including the use of antibiotics, physiotherapy, and regular follow-up examination using abdominal ultrasound, enhanced CT, and MR imaging (163). For pseudocysts $>6 \mathrm{~cm}$ that persist for $>6$ weeks, surgical or endoscopic intervention is recommended when symptomatic, as the cyst wall is mature and, thus, cannot resolve spontaneously $(164,165)$. Several approaches can be used to drain pseudocysts, including surgical, percutaneous, and endoscopic approaches. Several studies have confirmed endoscopy as one of the most common and effective approaches for fluid drainage, being associated with a lower rate of mortality and complications compared to surgical and percutaneous approaches $(166,167)$. Based on this evidence, endoscopic techniques, such as trans-mural drainage, trans-papillary drainage, and stenting, are best choice for the treatment of symptomatic pseudocysts (168).

\section{Infected acute necrotic collection and walled-off necrosis}

IPN refers to the collection of acute necrotic by-products or walled-off necrosis secondary to infection (13). Imaging has a high diagnostic value for IPN, with characteristic features including the "bubble sign" (i.e., a gas/liquid level) 
and morphological features of cellulitis observed on CT in the area of necrosis $(13,169)$. Clinical symptoms, such as SIRS and organ dysfunction, can provide auxiliary indicators for diagnosis $(5,16,170)$. Bacterial culture from pancreatic tissue, obtained by percutaneous fine needle aspiration (FNA), may also assist in the diagnosis of IPN (171), although Japanese guidelines recommend against the routine use of FNA, indicating that FNA should be used for patients with suspected fungal infection or an infection that has not been effectively controlled using multiple antibiotics (172). For patients with clinically confirmed or highly suspected IPN, surgical intervention is an important treatment method (173) and should follow the "3D" principles, namely delay, drain, and debride (174). Specifically, the surgery should be delayed to 4-6 weeks after the onset of IPN. Necrotic tissue is sufficiently liquefied to form an envelope, providing a clear boundary relative to surrounding tissues, which maximizes retention of normal functioning pancreatic tissue. Surgery can be effective in lowering the occurrence of intestinal fistula, bleeding, and infection-related complications. Studies have reported an incidence rate of complication of 34-95\% using traditional open abdominal debridement, with an associated mortality rate of 5.6-39\% (175). In recent years, the treatment of IPN has been expanded beyond a single approach, with the approach selected based on the patient's health status, degree and extent of necrosis, and other relevant clinical measures. To this end, a "step-up" approach has gradually become the gold standard treatment for IPN (176-178). Two 10-year follow-up studies have reported on the benefits of a step-up approach relative to open necrosectomy, without an increased risk of mortality, reintervention, and long-term complications $(179,180)$. The step-up approach uses PCD or endoscopic necrosectomy as the initial treatment with the purpose of alleviating the systematic inflammatory response of IPN $(181,182)$. With IPN progression, laparoscopic necrosectomy (LN), or RN can be performed, with the use of the sinus tract created by PCD being a good approach for these two surgical procedures (183). The surgical goal of the step-up approach is to control the systemic inflammatory response, rather than to remove the necrotic tissue completely, thereby reducing the rate of postoperative complications and mortality $(4,184)$. Due to the complexity and variability of presentation of SAP, multidisciplinary collaboration is required, with the focus being on minimally invasive treatment (185). In this way, the step-up surgical approach can include the full scope of treatment possible for IPN.

\section{Summary}

$\mathrm{AP}$ is a common disease of the digestive system, with its pathogenesis being multifactorial, including trypsinogen activation, $\mathrm{Ca}^{2+}$ overload, ER stress, mitochondrial dysfunction, impaired autophagy, and exosomes. AP can progress to SAP, with a high risk of mortality, without effective control. Therefore, there is a need for clinicians to regularly evaluate patients' disease status, determine the severity of the disease, and provide active treatment, as needed, including fluid resuscitation, nutritional support, analgesics, and etiological treatment. For patients with local complications, appropriate treatment for SAP is necessary, including drainage, ERCP, cholecystectomy, and necrotic tissue debridement. Although we may take positive measures to treat $\mathrm{AP}$, these complications can still significantly reduce life quality and prognosis. Consequently, the pathogenesis of AP needs to be further explored to identify effective therapeutic targets and improve therapeutic effect and patients' quality of life.

\section{Acknowledgments}

Funding: This work was supported by the Beijing Municipal Science \& Technology Commission, Capital Research and Demonstration Application of Clinical Diagnosis and Treatment Technology (No. Z191100006619038 and No. Z171100001017077), the Capital Health Research and Development of Special (No. 2020-1-2012), and Capital Medical University Clinical Medicine Advanced Sophisticated Subject Construction Project (No. 1192070312).

\section{Footnote}

Reporting Checklist: The authors have completed the Narrative Review reporting checklist. Available at http:// dx.doi.org/10.21037/atm-20-4802

Conflicts of Interest: All authors have completed the ICMJE uniform disclosure form (available at http://dx.doi. org/10.21037/atm-20-4802). The authors have no conflicts of interest to declare.

Ethics Statement: The authors are accountable for all aspects of the work in ensuring that questions related to the accuracy or integrity of any part of the work are 
appropriately investigated and resolved.

Open Access Statement: This is an Open Access article distributed in accordance with the Creative Commons Attribution-NonCommercial-NoDerivs 4.0 International License (CC BY-NC-ND 4.0), which permits the noncommercial replication and distribution of the article with the strict proviso that no changes or edits are made and the original work is properly cited (including links to both the formal publication through the relevant DOI and the license). See: https://creativecommons.org/licenses/by-nc-nd/4.0/.

\section{References}

1. Petrov MS, Yadav D. Global epidemiology and holistic prevention of pancreatitis. Nat Rev Gastroenterol Hepatol 2019;16:175-84.

2. Roberts SE, Morrison-Rees S, John A, et al. The incidence and aetiology of acute pancreatitis across Europe. Pancreatology 2017;17:155-65.

3. Boxhoorn L, Voermans RP, Bouwense SA, et al. Acute pancreatitis. Lancet 2020;396:726-34.

4. Trikudanathan G, Wolbrink DRJ, van Santvoort $\mathrm{HC}$, et al. Current concepts in severe acute and necrotizing pancreatitis: an evidence-based approach. Gastroenterology 2019;156:1994-2007.e3.

5. van Brunschot S, van Grinsven J, Voermans RP, et al. Transluminal endoscopic step-up approach versus minimally invasive surgical step-up approach in patients with infected necrotising pancreatitis (TENSION trial): design and rationale of a randomised controlled multicenter trial [ISRCTN09186711]. BMC Gastroenterol 2013;13:161.

6. Bang JY, Arnoletti JP, Holt BA, et al. An endoscopic transluminal approach, compared with minimally invasive surgery, reduces complications and costs for patients with necrotizing pancreatitis. Gastroenterology 2019;156:1027-40.e3.

7. Shah AP, Mourad MM, Bramhall SR. Acute pancreatitis: current perspectives on diagnosis and management. J Inflamm Res 2018;11:77-85.

8. Machicado JD, Gougol A, Stello K, et al. Acute pancreatitis has a long-term deleterious effect on physical health related quality of life. Clin Gastroenterol Hepatol 2017;15:1435-43.e2.

9. Hollemans RA, Hallensleben NDL, Mager DJ, et al. Pancreatic exocrine insufficiency following acute pancreatitis: Systematic review and study level meta-analysis. Pancreatology 2018;18:253-62.

10. Sankaran SJ, Xiao AY, Wu LM, et al. Frequency of progression from acute to chronic pancreatitis and risk factors: a meta-analysis. Gastroenterology 2015;149:1490-500.e1.

11. Das SL, Singh PP, Phillips AR, et al. Newly diagnosed diabetes mellitus after acute pancreatitis: a systematic review and meta-analysis. Gut 2014;63:818-31.

12. Guo XY, Xiao F, Li J, et al. Exosomes and pancreatic diseases: status, challenges, and hopes. Int J Biol Sci 2019;15:1846-60.

13. Banks PA, Bollen TL, Dervenis C, et al. Classification of acute pancreatitis--2012: revision of the Atlanta classification and definitions by international consensus. Gut 2013;62:102-11.

14. Taydas O, Unal E, Karaosmanoglu AD, et al. Accuracy of early CT findings for predicting disease course in patients with acute pancreatitis. Jpn J Radiol 2018;36:151-8.

15. Crockett SD, Wani S, Gardner TB, et al. American Gastroenterological Association Institute guideline on initial management of acute pancreatitis. Gastroenterology 2018;154:1096-101.

16. Tenner S, Baillie J, DeWitt J, et al. American College of Gastroenterology guideline: management of acute pancreatitis. Am J Gastroenterol 2013;108:1400-15; 1416.

17. Working Group IAPAPAAPG. IAP/APA evidence-based guidelines for the management of acute pancreatitis. Pancreatology 2013;13:e1-15.

18. Brand M, Gotz A, Zeman F, et al. Acute necrotizing pancreatitis: laboratory, clinical, and imaging findings as predictors of patient outcome. AJR Am J Roentgenol 2014;202:1215-31.

19. Pieńkowska J, Gwoździewicz K, Skrobisz-Balandowska $\mathrm{K}$, et al. Perfusion-CT--can we predict acute pancreatitis outcome within the first 24 hours from the onset of symptoms? PLoS One 2016;11:e0146965.

20. Mikó A, Vigh É, Mátrai P, et al. Computed tomography severity index vs. other indices in the prediction of severity and mortality in acute pancreatitis: a predictive accuracy meta-analysis. Front Physiol 2019;10:1002.

21. Biberci Keskin E, Taslidere B, Kochan K, et al. Comparison of scoring systems used in acute pancreatitis for predicting major adverse events. Gastroenterol Hepatol 2020; 43:193-9.

22. Vriens PW, van de Linde P, Slotema ET, et al. Computed tomography severity index is an early prognostic tool for acute pancreatitis. J Am Coll Surg 2005;201:497-502.

23. Braha J, Tenner S. Fluid collections and pseudocysts as a 
complication of acute pancreatitis. Gastrointest Endosc Clin N Am 2018;28:123-30.

24. Xiao B, Xu HB, Jiang ZQ, et al. Current concepts for the diagnosis of acute pancreatitis by multiparametric magnetic resonance imaging. Quant Imaging Med Surg 2019;9:1973-85.

25. Garg PK, Singh VP. Organ failure due to systemic injury in acute pancreatitis. Gastroenterology 2019;156:2008-23.

26. Dellinger EP, Forsmark CE, Layer P, et al. Determinant-based classification of acute pancreatitis severity: an international multidisciplinary consultation. Ann Surg 2012;256:875-80.

27. Feng S, Wei Q, Hu Q, et al. Research progress on the relationship between acute pancreatitis and calcium overload in acinar cells. Dig Dis Sci 2019;64:25-38.

28. Carreras-Sureda A, Pihan P, Hetz C. Calcium signaling at the endoplasmic reticulum: fine-tuning stress responses. Cell Calcium 2018;70:24-31.

29. Voronina S, Collier D, Chvanov M, et al. The role of $\mathrm{Ca} 2+$ influx in endocytic vacuole formation in pancreatic acinar cells. Biochem J 2015;465:405-12.

30. Biczo G, Vegh ET, Shalbueva N, et al. Mitochondrial dysfunction, through impaired autophagy, leads to endoplasmic reticulum stress, deregulated lipid metabolism, and pancreatitis in animal models. Gastroenterology 2018;154:689-703.

31. Mukherjee R, Mareninova OA, Odinokova IV, et al. Mechanism of mitochondrial permeability transition pore induction and damage in the pancreas: inhibition prevents acute pancreatitis by protecting production of ATP. Gut 2016;65:1333-46.

32. Lur G, Sherwood MW, Ebisui E, et al. InsP(3)receptors and Orai channels in pancreatic acinar cells: co-localization and its consequences. Biochem J 2011;436:231-9.

33. Maléth J, Hegyi P. Ca2+ toxicity and mitochondrial damage in acute pancreatitis: translational overview. Philos Trans R Soc Lond B Biol Sci 2016;371:20150425.

34. Criddle DN, McLaughlin E, Murphy JA, et al. The pancreas misled: signals to pancreatitis. Pancreatology 2007;7:436-46.

35. Peng S, Gerasimenko JV, Tsugorka T, et al. Calcium and adenosine triphosphate control of cellular pathology: asparaginase-induced pancreatitis elicited via protease-activated receptor 2. Philos Trans R Soc Lond B Biol Sci 2016;371:20150423.

36. Li Z, Xu C, Tao Y, et al. Anisodamine alleviates lipopolysaccharide-induced pancreatic acinar cell injury through NLRP3 inflammasome and NF-kappaB signaling pathway. J Recept Signal Transduct Res 2020;40:58-66.

37. $\mathrm{Pu}$ WL, Bai RY, Zhou K, et al. Baicalein attenuates pancreatic inflammatory injury through regulating MAPK, STAT 3 and NF-kappaB activation. Int Immunopharmacol 2019;72:204-10.

38. Wen L, Voronina S, Javed MA, et al. Inhibitors of ORAI1 prevent cytosolic calcium-associated injury of human pancreatic acinar cells and acute pancreatitis in 3 mouse models. Gastroenterology 2015;149:481-92.e7.

39. Javed MA, Wen L, Awais M, et al. TRO40303 ameliorates alcohol-induced pancreatitis through reduction of fatty acid ethyl ester-induced mitochondrial injury and necrotic cell death. Pancreas 2018;47:18-24.

40. Atar D, Arheden H, Berdeaux A, et al. Effect of intravenous TRO40303 as an adjunct to primary percutaneous coronary intervention for acute ST-elevation myocardial infarction: MITOCARE study results. Eur Heart J 2015;36:112-9.

41. Schaller S, Michaud M, Latyszenok V, et al. TRO40303, a mitochondrial-targeted cytoprotective compound, provides protection in hepatitis models. Pharmacol Res Perspect 2015;3:e00144.

42. Márta K, Szabó AN, Pécsi D, et al. High versus low energy administration in the early phase of acute pancreatitis (GOULASH trial): protocol of a multicentre randomised double-blind clinical trial. BMJ Open 2017;7:e015874.

43. Dawra R, Sah RP, Dudeja V, et al. Intra-acinar trypsinogen activation mediates early stages of pancreatic injury but not inflammation in mice with acute pancreatitis. Gastroenterology 2011;141:2210-7.e2.

44. Chvanov M, De Faveri F, Moore D, et al. Intracellular rupture, exocytosis and actin interaction of endocytic vacuoles in pancreatic acinar cells: initiating events in acute pancreatitis. J Physiol 2018;596:2547-64.

45. Talukdar R, Sareen A, Zhu H, et al. Release of cathepsin $\mathrm{B}$ in cytosol causes cell death in acute pancreatitis. Gastroenterology 2016;151:747-58.e5.

46. Han J, Zhong CQ, Zhang DW. Programmed necrosis: backup to and competitor with apoptosis in the immune system. Nat Immunol 2011;12:1143-9.

47. Liu Y, Liu T, Lei T, et al. RIP1/RIP3-regulated necroptosis as a target for multifaceted disease therapy (Review). Int J Mol Med 2019;44:771-86.

48. Zhang L, Feng Q, Wang T. Necrostatin-1 protects against paraquat-induced cardiac contractile dysfunction via RIP1-RIP3-MLKL-dependent necroptosis pathway. Cardiovasc Toxicol 2018;18:346-55.

49. Harris PA, Berger SB, Jeong JU, et al. Discovery of a 
first-in-class receptor interacting protein 1 (RIP1) kinase specific clinical candidate (GSK2982772) for the treatment of inflammatory diseases. J Med Chem 2017;60:1247-61.

50. Ren Y, Su Y, Sun L, et al. Discovery of a highly potent, selective, and metabolically stable inhibitor of receptor-interacting protein 1 (RIP1) for the treatment of systemic inflammatory response syndrome. J Med Chem 2017;60:972-86.

51. Louhimo J, Steer ML, Perides G. Necroptosis is an important severity determinant and potential therapeutic target in experimental severe pancreatitis. Cell Mol Gastroenterol Hepatol 2016;2:519-35.

52. Wang G, Qu FZ, Li L, et al. Necroptosis: a potential, promising target and switch in acute pancreatitis. Apoptosis 2016;21:121-9.

53. He S, Wang L, Miao L, et al. Receptor interacting protein kinase-3 determines cellular necrotic response to TNF-alpha. Cell 2009;137:1100-11.

54. Zhan X, Wan J, Zhang G, et al. Elevated intracellular trypsin exacerbates acute pancreatitis and chronic pancreatitis in mice. Am J Physiol Gastrointest Liver Physiol 2019;316:G816-25.

55. Sendler M, Weiss FU, Golchert J, et al. Cathepsin B-mediated activation of trypsinogen in endocytosing macrophages increases severity of pancreatitis in mice. Gastroenterology 2018;154:704-18.e10.

56. Gea-Sorlí S, Closa D. Role of macrophages in the progression of acute pancreatitis. World J Gastrointest Pharmacol Ther 2010;1:107-11.

57. Antonucci L, Fagman JB, Kim JY, et al. Basal autophagy maintains pancreatic acinar cell homeostasis and protein synthesis and prevents ER stress. Proc Natl Acad Sci U S A 2015;112:E6166-74.

58. Gukovskaya AS, Gukovsky I, Algul H, et al. Autophagy, inflammation, and immune dysfunction in the pathogenesis of pancreatitis. Gastroenterology 2017;153:1212-26.

59. Gukovskaya AS, Gorelick FS, Groblewski GE, et al. Recent insights into the pathogenic mechanism of pancreatitis: role of acinar cell organelle disorders. Pancreas 2019;48:459-70.

60. Mizushima N, Yamamoto A, Matsui M, et al. In vivo analysis of autophagy in response to nutrient starvation using transgenic mice expressing a fluorescent autophagosome marker. Mol Biol Cell 2004;15:1101-11.

61. Mareninova OA, Hermann K, French SW, et al. Impaired autophagic flux mediates acinar cell vacuole formation and trypsinogen activation in rodent models of acute pancreatitis. J Clin Invest 2009;119:3340-55.
62. Diakopoulos KN, Lesina M, Wormann S, et al. Impaired autophagy induces chronic atrophic pancreatitis in mice via sex- and nutrition-dependent processes. Gastroenterology 2015;148:626-38.e17.

63. Wang $\mathrm{H}, \mathrm{Li} \mathrm{C}$, Jiang $\mathrm{Y}$, et al. Effects of bacterial translocation and autophagy on acute lung injury induced by severe acute pancreatitis. Gastroenterol Res Pract 2020;2020:8953453.

64. Feng D, Park O, Radaeva S, et al. Interleukin-22 ameliorates cerulein-induced pancreatitis in mice by inhibiting the autophagic pathway. Int J Biol Sci 2012;8:249-57.

65. Lee HJ, Yoon YS, Lee SJ. Mechanism of neuroprotection by trehalose: controversy surrounding autophagy induction. Cell Death Dis 2018;9:712.

66. Hetz C, Chevet E, Oakes SA. Proteostasis control by the unfolded protein response. Nat Cell Biol 2015;17:829-38.

67. Wu JS, Li WM, Chen YN, et al. Endoplasmic reticulum stress is activated in acute pancreatitis. J Dig Dis 2016;17:295-303.

68. Lugea A, Gerloff A, Su HY, et al. The combination of alcohol and cigarette smoke induces endoplasmic reticulum stress and cell death in pancreatic acinar cells. Gastroenterology 2017;153:1674-86.

69. Zhao Q, Tang X, Huang J, et al. Melatonin attenuates endoplasmic reticulum stress in acute pancreatitis. Pancreas 2018;47:884-91.

70. Barrera K, Stanek A, Okochi K, et al. Acinar cell injury induced by inadequate unfolded protein response in acute pancreatitis. World J Gastrointest Pathophysiol 2018;9:37-46.

71. Walter P, Ron D. The unfolded protein response: from stress pathway to homeostatic regulation. Science 2011;334:1081-6.

72. Ron D, Walter P. Signal integration in the endoplasmic reticulum unfolded protein response. Nat Rev Mol Cell Biol 2007;8:519-29.

73. Aoi K, Nishio A, Okazaki T, et al. Inhibition of the dephosphorylation of eukaryotic initiation factor 2alpha ameliorates murine experimental pancreatitis. Pancreatology 2019;19:548-56.

74. Ghosh R, Wang L, Wang ES, et al. Allosteric inhibition of the IRE1alpha RNase preserves cell viability and function during endoplasmic reticulum stress. Cell 2014;158:534-48.

75. Kapuy O, Marton M, Banhegyi G, et al. Multiple systemlevel feedback loops control life-and-death decisions in endoplasmic reticulum stress. FEBS Lett 
2020;594:1112-23.

76. Jin HZ, Yang XJ, Zhao KL, et al. Apocynin alleviates lung injury by suppressing NLRP3 inflammasome activation and NF-kappaB signaling in acute pancreatitis. Int Immunopharmacol 2019;75:105821.

77. Jakkampudi A, Jangala R, Reddy BR, et al. NF-kappaB in acute pancreatitis: mechanisms and therapeutic potential. Pancreatology 2016;16:477-88.

78. Malo A, Kruger B, Goke B, et al. 4-Phenylbutyric acid reduces endoplasmic reticulum stress, trypsin activation, and acinar cell apoptosis while increasing secretion in rat pancreatic acini. Pancreas 2013;42:92-101.

79. Lee PJ, Modha K, Chua T, et al. Association of statins with decreased acute pancreatitis severity: a propensity score analysis. J Clin Gastroenterol 2018;52:742-6.

80. Bonjoch L, Casas V, Carrascal M, et al. Involvement of exosomes in lung inflammation associated with experimental acute pancreatitis. J Pathol 2016;240:235-45.

81. Wu XB, Sun HY, Luo ZL, et al. Plasma-derived exosomes contribute to pancreatitis-associated lung injury by triggering NLRP3-dependent pyroptosis in alveolar macrophages. Biochim Biophys Acta Mol Basis Dis 2020;1866:165685.

82. Yang Y, Huang Q, Luo C, et al. MicroRNAs in acute pancreatitis: from pathogenesis to novel diagnosis and therapy. J Cell Physiol 2020;235:1948-61.

83. Hudson MB, Woodworth-Hobbs ME, Zheng B, et al. miR-23a is decreased during muscle atrophy by a mechanism that includes calcineurin signaling and exosome-mediated export. Am J Physiol Cell Physiol 2014;306:C551-8.

84. Wang T, Jiang L, Wei X, et al. MiR-21-3p aggravates injury in rats with acute hemorrhagic necrotizing pancreatitis by activating TRP signaling pathway. Biomed Pharmacother 2018;107:1744-53.

85. Cen ME, Wang F, Su Y, et al. Gastrointestinal microecology: a crucial and potential target in acute pancreatitis. Apoptosis 2018;23:377-87.

86. Munir F, Jamshed MB, Shahid N, et al. Current status of diagnosis and Mesenchymal stem cells therapy for acute pancreatitis. Physiol Rep 2019;7:e14170.

87. Zhao Y, Gan Y, Xu G, et al. Exosomes from MSCs overexpressing microRNA-223-3p attenuate cerebral ischemia through inhibiting microglial M1 polarization mediated inflammation. Life Sci 2020;260:118403.

88. Perner A, Haase N, Guttormsen AB, et al. Hydroxyethyl starch 130/0.42 versus Ringer's acetate in severe sepsis. N Engl J Med 2012;367:124-34.
89. Perel P, Roberts I, Ker K. Colloids versus crystalloids for fluid resuscitation in critically ill patients. Cochrane Database Syst Rev 2013;(2):CD000567.

90. Rich K. Review of article: effects of fluid resuscitation with colloids versus crystalloids on mortality in critically ill patients presenting with hypovolemic shock the CRISTAL randomized trial by Djillali Annane, Shidasp Siami, Samir Jaber, et al (JAMA 2013;310:1809-17). J Vasc Nurs 2014;32:70-1.

91. Annane D, Siami S, Jaber S, et al. Effects of fluid resuscitation with colloids vs crystalloids on mortality in critically ill patients presenting with hypovolemic shock: the CRISTAL randomized trial. JAMA 2013;310:1809-17.

92. Wu BU, Hwang JQ, Gardner TH, et al. Lactated Ringer's solution reduces systemic inflammation compared with saline in patients with acute pancreatitis. Clin Gastroenterol Hepatol 2011;9:710-7.e1.

93. de-Madaria E, Herrera-Marante I, Gonzalez-Camacho V, et al. Fluid resuscitation with lactated Ringer's solution vs normal saline in acute pancreatitis: a triple-blind, randomized, controlled trial. United European Gastroenterol J 2018;6:63-72.

94. Choosakul S, Harinwan K, Chirapongsathorn S, et al. Comparison of normal saline versus Lactated Ringer's solution for fluid resuscitation in patients with mild acute pancreatitis, a randomized controlled trial. Pancreatology 2018;18: 30083-8.

95. Lobo DN, Awad S. Should chloride-rich crystalloids remain the mainstay of fluid resuscitation to prevent 'pre-renal' acute kidney injury?: con. Kidney Int 2014;86:1096-105.

96. Young P, Bailey M, Beasley R, et al. Effect of a buffered crystalloid solution vs saline on acute kidney injury among patients in the intensive care unit: the SPLIT randomized clinical trial. JAMA 2015;314:1701-10.

97. de-Madaria E, Banks PA, Moya-Hoyo N, et al. Early factors associated with fluid sequestration and outcomes of patients with acute pancreatitis. Clin Gastroenterol Hepatol 2014;12:997-1002.

98. Mao EQ, Fei J, Peng YB, et al. Rapid hemodilution is associated with increased sepsis and mortality among patients with severe acute pancreatitis. Chin Med J (Engl) 2010;123:1639-44.

99. Mao EQ, Tang YQ, Fei J, et al. Fluid therapy for severe acute pancreatitis in acute response stage. Chin Med J (Engl) 2009; 122:169-73.

100. Yealy DM, Kellum JA, Huang DT, et al. A randomized trial of protocol-based care for early septic shock. N Engl J 
Med 2014;370:1683-93.

101.Peake SL, Delaney A, Bailey M, et al. Goal-directed resuscitation for patients with early septic shock. N Engl J Med 2014;371:1496-506.

102. Gupta RG, Hartigan SM, Kashiouris MG, et al. Early goal-directed resuscitation of patients with septic shock: current evidence and future directions. Crit Care 2015;19:286.

103. Mole DJ, Hall A, McKeown D, et al. Detailed fluid resuscitation profiles in patients with severe acute pancreatitis. HPB (Oxford) 2011;13:51-8.

104.Aggarwal A, Manrai M, Kochhar R. Fluid resuscitation in acute pancreatitis. World J Gastroenterol 2014;20:18092-103.

105.Gülen B, Dur A, Serinken M, et al. Pain treatment in patients with acute pancreatitis: a randomized controlled trial. Turk J Gastroenterol 2016;27:192-6.

106. Barlass U, Dutta R, Cheema H, et al. Morphine worsens the severity and prevents pancreatic regeneration in mouse models of acute pancreatitis. Gut 2018;67:600-2.

107.Basurto Ona X, Rigau Comas D, Urrutia G. Opioids for acute pancreatitis pain. Cochrane Database Syst Rev 2013;7:CD009179.

108. Stigliano S, Sternby H, de Madaria E, et al. Early management of acute pancreatitis: A review of the best evidence. Dig Liver Dis 2017;49:585-94.

109.Lee PJ, Papachristou GI. New insights into acute pancreatitis. Nat Rev Gastroenterol Hepatol 2019;16:479-96.

110.van Dijk SM, Hallensleben NDL, van Santvoort HC, et al. Acute pancreatitis: recent advances through randomised trials. Gut 2017;66:2024-32.

111. Cadena AJ, Habib S, Rincon F, et al. The benefits of parenteral nutrition $(\mathrm{PN})$ versus enteral nutrition $(\mathrm{EN})$ among adult critically ill patients: what is the evidence? A literature review. J Intensive Care Med 2020;35:615-26.

112. Capurso G, Zerboni G, Signoretti M, et al. Role of the gut barrier in acute pancreatitis. J Clin Gastroenterol 2012;46 Suppl:S46-51.

113.Li XY, He C, Zhu Y, et al. Role of gut microbiota on intestinal barrier function in acute pancreatitis. World J Gastroenterol 2020;26:2187-93.

114. Vaughn VM, Shuster D, Rogers MAM, et al. Early versus delayed feeding in patients with acute pancreatitis: a systematic review. Ann Intern Med 2017;166:883-92.

115.Li W, Liu J, Zhao S, et al. Safety and efficacy of total parenteral nutrition versus total enteral nutrition for patients with severe acute pancreatitis: a meta-analysis. J
Int Med Res 2018;46:3948-58.

116.Elke G, van Zanten AR, Lemieux M, et al. Enteral versus parenteral nutrition in critically ill patients: an updated systematic review and meta-analysis of randomized controlled trials. Crit Care 2016;20:117.

117. Reintam Blaser A, Starkopf J, Alhazzani W, et al. Early enteral nutrition in critically ill patients: ESICM clinical practice guidelines. Intensive Care Med 2017;43:380-98.

118. Qi D, Yu B, Huang J, et al. Meta-analysis of early enteral nutrition provided within 24 hours of admission on clinical outcomes in acute pancreatitis. JPEN J Parenter Enteral Nutr 2018;42:1139-47.

119. Harvey SE, Parrott F, Harrison DA, et al. A multicentre, randomised controlled trial comparing the clinical effectiveness and cost-effectiveness of early nutritional support via the parenteral versus the enteral route in critically ill patients (CALORIES). Health Technol Assess 2016;20:1-144.

120. Reignier J, Boisrame-Helms J, Brisard L, et al. Enteral versus parenteral early nutrition in ventilated adults with shock: a randomised, controlled, multicentre, open-label, parallel-group study (NUTRIREA-2). Lancet 2018;391:133-43.

121. Wu XM, Liao YW, Wang HY, et al. When to initialize enteral nutrition in patients with severe acute pancreatitis? A retrospective review in a single institution experience (2003-2013). Pancreas 2015;44:507-11.

122.Tian F, Heighes PT, Allingstrup MJ, et al. Early enteral nutrition provided within 24 hours of ICU admission: a meta-analysis of randomized controlled trials. Crit Care Med 2018;46:1049-56.

123. Song J, Zhong Y, Lu X, et al. Enteral nutrition provided within 48 hours after admission in severe acute pancreatitis: a systematic review and meta-analysis. Medicine (Baltimore) 2018;97:e11871.

124. Li JY, Yu T, Chen GC, et al. Enteral nutrition within 48 hours of admission improves clinical outcomes of acute pancreatitis by reducing complications: a meta-analysis. PLoS One 2013;8:e64926.

125. Bakker OJ, van Brunschot S, Farre A, et al. Timing of enteral nutrition in acute pancreatitis: meta-analysis of individuals using a single-arm of randomised trials. Pancreatology 2014;14:340-6.

126. Eatock FC, Chong P, Menezes N, et al. A randomized study of early nasogastric versus nasojejunal feeding in severe acute pancreatitis. Am J Gastroenterol 2005;100:432-9.

127.Zhu Y, Yin H, Zhang R, et al. Nasogastric nutrition 
versus nasojejunal nutrition in patients with severe acute pancreatitis: a meta-analysis of randomized controlled trials. Gastroenterol Res Pract 2016;2016:6430632.

128. Singh N, Sharma B, Sharma M, et al. Evaluation of early enteral feeding through nasogastric and nasojejunal tube in severe acute pancreatitis: a noninferiority randomized controlled trial. Pancreas 2012;41:153-9.

129. Kumar A, Singh N, Prakash S, et al. Early enteral nutrition in severe acute pancreatitis: a prospective randomized controlled trial comparing nasojejunal and nasogastric routes. J Clin Gastroenterol 2006;40:431-4.

130. Vege SS, DiMagno MJ, Forsmark CE, et al. Initial medical treatment of acute pancreatitis: American Gastroenterological Association Institute Technical Review. Gastroenterology 2018;154:1103-39.

131. Ma J, Pendharkar SA, O'Grady G, et al. Effect of nasogastric tube feeding vs Nil per Os on dysmotility in acute pancreatitis: results of a randomized controlled trial. Nutr Clin Pract 2016;31:99-104.

132.Horibe M, Nishizawa T, Suzuki H, et al. Timing of oral refeeding in acute pancreatitis: a systematic review and meta-analysis. United European Gastroenterol J 2016;4:725-32.

133. Bakker OJ, van Brunschot S, van Santvoort HC, et al. Early versus on-demand nasoenteric tube feeding in acute pancreatitis. N Engl J Med 2014;371:1983-93.

134. Stimac D, Poropat G, Hauser G, et al. Early nasojejunal tube feeding versus nil-by-mouth in acute pancreatitis: a randomized clinical trial. Pancreatology 2016;16:523-8.

135.Lim CL, Lee W, Liew YX, et al. Role of antibiotic prophylaxis in necrotizing pancreatitis: a meta-analysis. J Gastrointest Surg 2015;19:480-91.

136. Mandal AK, Chaudhary S, Shrestha B, et al. Efficacy of prophylactic use of ciprofloxacin and metronidazole in mild and moderately severe acute pancreatitis. JNMA J Nepal Med Assoc 2017;56:207-10.

137. Nakaharai K, Morita K, Jo T, et al. Early prophylactic antibiotics for severe acute pancreatitis: a population-based cohort study using a nationwide database in Japan. J Infect Chemother 2018;24:753-8.

138. Mourad MM, Evans R, Kalidindi V, et al. Prophylactic antibiotics in acute pancreatitis: endless debate. Ann R Coll Surg Engl 2017;99:107-12.

139. Rhodes A, Evans LE, Alhazzani W, et al. Surviving Sepsis Campaign: international guidelines for management of sepsis and septic shock: 2016. Crit Care Med 2017;45:486-552.

140.Moody N, Adiamah A, Yanni F, et al. Meta-analysis of randomized clinical trials of early versus delayed cholecystectomy for mild gallstone pancreatitis. Br J Surg 2019;106:1442-51.

141. Noel R, Arnelo U, Lundell L, et al. Index versus delayed cholecystectomy in mild gallstone pancreatitis: results of a randomized controlled trial. HPB (Oxford) 2018;20:932-8.

142. Yang DJ, Lu HM, Guo Q, et al. Timing of laparoscopic cholecystectomy after mild biliary pancreatitis: a systematic review and meta-analysis. J Laparoendosc Adv Surg Tech A 2018;28:379-88.

143.Lyu YX, Cheng YX, Jin HF, et al. Same-admission versus delayed cholecystectomy for mild acute biliary pancreatitis: a systematic review and meta-analysis. BMC Surg 2018;18:111.

144.Davoodabadi A, Beigmohammadi E, Gilasi H, et al. Optimizing cholecystectomy time in moderate acute biliary pancreatitis: a randomized clinical trial study. Heliyon 2020;6:e03388.

145.Jee SL, Jarmin R, Lim KF, et al. Outcomes of early versus delayed cholecystectomy in patients with mild to moderate acute biliary pancreatitis: a randomized prospective study. Asian J Surg 2018;41:47-54.

146.Jensen KK, Roth NO, Krarup PM, et al. Surgical management of acute cholecystitis in a nationwide Danish cohort. Langenbecks Arch Surg 2019;404:589-97.

147. Mahalingam S, Langdon J, Muniraj T, et al. Endoscopic retrograde cholangiopancreatography: deciphering the black and white. Curr Probl Diagn Radiol 2021;50:74-84.

148. Malli A, Durkin C, Groce JR, et al. Unavailability of endoscopic retrograde cholangiography adversely impacts hospital outcomes of acute biliary pancreatitis: a national survey and propensity-matched analysis. Pancreas 2020;49:39-45.

149. Schepers NJ, Bakker OJ, Besselink MG, et al. Early biliary decompression versus conservative treatment in acute biliary pancreatitis (APEC trial): study protocol for a randomized controlled trial. Trials 2016;17:5.

150.Nealon WH, Bawduniak J, Walser EM. Appropriate timing of cholecystectomy in patients who present with moderate to severe gallstone-associated acute pancreatitis with peripancreatic fluid collections. Ann Surg 2004;239:741-9; discussion 749-51.

151. Burstow MJ, Yunus RM, Hossain MB, et al. Meta-analysis of early endoscopic retrograde cholangiopancreatography (ERCP) +/- endoscopic sphincterotomy (ES) versus conservative management for gallstone pancreatitis (GSP). Surg Laparosc Endosc Percutan Tech 2015;25:185-203. 152.Li J, Chen J, Tang W. The consensus of integrative 
diagnosis and treatment of acute pancreatitis-2017. J Evid Based Med 2019;12:76-88.

153.Pezzilli R, Zerbi A, Campra D, et al. Consensus guidelines on severe acute pancreatitis. Dig Liver Dis 2015;47:532-43.

154. Stefanutti C, Labbadia G, Morozzi C. Severe hypertriglyceridemia-related acute pancreatitis. Ther Apher Dial 2013;17:130-7.

155. Chang CT, Tsai TY, Liao HY, et al. Double filtration plasma apheresis shortens hospital admission duration of patients with severe hypertriglyceridemia-associated acute pancreatitis. Pancreas 2016;45:606-12.

156. Gavva C, Sarode R, Agrawal D, et al. Therapeutic plasma exchange for hypertriglyceridemia induced pancreatitis: a rapid and practical approach. Transfus Apher Sci 2016;54:99-102.

157. Berglund L, Brunzell JD, Goldberg AC, et al. Treatment options for hypertriglyceridemia: from risk reduction to pancreatitis. Best Pract Res Clin Endocrinol Metab 2014;28:423-37.

158.He WH, Yu M, Zhu Y, et al. Emergent triglyceride-lowering therapy with early high-volume hemofiltration against low-molecular-weight heparin combined with insulin in hypertriglyceridemic pancreatitis: a prospective randomized controlled trial. J Clin Gastroenterol 2016;50:772-8.

159. Adiamah A, Psaltis E, Crook M, et al. A systematic review of the epidemiology, pathophysiology and current management of hyperlipidaemic pancreatitis. Clin Nutr 2018;37:1810-22.

160. Dupont B, Musikas M, Dao MT, et al. Timing and route of enteral nutrition in severe acute pancreatitis? Pancreas 2016;45:e20.

161.Kamal A, Singh VK, Akshintala VS, et al. CT and MRI assessment of symptomatic organized pancreatic fluid collections and pancreatic duct disruption: an interreader variability study using the revised Atlanta classification 2012. Abdom Imaging 2015;40:1608-16.

162.Lancaster A, Zwijacz M. Acute pancreatitis and fluid-filled collections: etiology and endoscopic management. Gastroenterol Nurs 2019;42:417-9.

163. Shahid H. Endoscopic management of pancreatic fluid collections. Transl Gastroenterol Hepatol 2019;4:15.

164. Theerasuwipakorn N, Tasneem AA, Kongkam P, et al. Walled-off peripancreatic fluid collections in Asian population: paradigm shift from surgical and percutaneous to endoscopic drainage. J Transl Int Med 2019;7:170-7.

165.Law R, Baron TH. Endoscopic management of pancreatic pseudocysts and necrosis. Expert Rev Gastroenterol Hepatol 2015;9:167-75.

166. Muthusamy VR, Chandrasekhara V, Acosta RD, et al. The role of endoscopy in the diagnosis and treatment of inflammatory pancreatic fluid collections. Gastrointest Endosc 2016;83:481-8.

167. Redwan AA, Hamad MA, Omar MA. Pancreatic pseudocyst dilemma: cumulative multicenter experience in management using endoscopy, laparoscopy, and open surgery. J Laparoendosc Adv Surg Tech A 2017;27:1022-30.

168. Yang D, Amin S, Gonzalez S, et al. Transpapillary drainage has no added benefit on treatment outcomes in patients undergoing EUS-guided transmural drainage of pancreatic pseudocysts: a large multicenter study. Gastrointest Endosc 2016;83:720-9.

169. Foster BR, Jensen KK, Bakis G, et al. Revised Atlanta classification for acute pancreatitis: a pictorial essay. Radiographics 2016;36:675-87.

170.Lariño-Noia J, de la Iglesia-García D, González-Lopez J, et al. Endoscopic drainage with local infusion of antibiotics to avoid necrosectomy of infected walled-off necrosis. Surg Endosc 2020. [Epub ahead of print]. doi: 10.1007/s00464020-07428-4.

171.van Baal MC, Bollen TL, Bakker OJ, et al. The role of routine fine-needle aspiration in the diagnosis of infected necrotizing pancreatitis. Surgery 2014;155:442-8.

172.Isaji S, Takada T, Mayumi T, et al. Revised Japanese guidelines for the management of acute pancreatitis 2015: revised concepts and updated points. J Hepatobiliary Pancreat Sci 2015;22:433-45.

173. Rana SS. An overview of walled-off pancreatic necrosis for clinicians. Expert Rev Gastroenterol Hepatol 2019;13:331-43.

174.Baron TH, DiMaio CJ, Wang AY, et al. American Gastroenterological Association clinical practice update: management of pancreatic necrosis. Gastroenterology 2020;158:67-75.e1.

175.Jones JD, Clark CJ, Dyer R, et al. Analysis of a step-up approach versus primary open surgical necrosectomy in the management of necrotizing pancreatitis: experience in a cohort of patients at a US Academic Medical Center. Pancreas 2018;47:1317-21.

176. Besselink MG, van Santvoort HC, Nieuwenhuijs VB, et al. Minimally invasive 'step-up approach' versus maximal necrosectomy in patients with acute necrotising pancreatitis (PANTER trial): design and rationale of a randomised controlled multicenter trial [ISRCTN13975868]. BMC 
Surg 2006;6:6

177.van Santvoort HC, Besselink MG, Bakker OJ, et al. A step-up approach or open necrosectomy for necrotizing pancreatitis. N Engl J Med 2010;362:1491-502.

178.van Brunschot S, van Grinsven J, van Santvoort HC, et al. Endoscopic or surgical step-up approach for infected necrotising pancreatitis: a multicentre randomised trial. Lancet 2018;391:51-8.

179. Hollemans RA, Bakker OJ, Boermeester MA, et al. Superiority of step-up approach vs open necrosectomy in long-term follow-up of patients with necrotizing pancreatitis. Gastroenterology 2019;156:1016-26.

180.Gupta R, Kulkarni A, Babu R, et al. Complications of percutaneous drainage in step-up approach for management of pancreatic necrosis: experience of 10 years from a tertiary care center. J Gastrointest Surg 2020;24:598-609.

Cite this article as: Zheng Z, Ding YX, Qu YX, Cao F, Li F. A narrative review of acute pancreatitis and its diagnosis, pathogenetic mechanism, and management. Ann Transl Med 2021;9(1):69. doi: 10.21037/atm-20-4802
181.Eid AI, Mueller P, Thabet A, et al. A step-up approach to infected abdominal fluid collections: not just for pancreatitis. Surg Infect (Larchmt) 2020;21:54-61 .

182. Bakker OJ, van Santvoort HC, van Brunschot S, et al. Endoscopic transgastric vs surgical necrosectomy for infected necrotizing pancreatitis: a randomized trial. JAMA 2012;307:1053-61.

183. Fong ZV, Fagenholz PJ. Minimally invasive debridement for infected pancreatic necrosis. J Gastrointest Surg 2019;23:185-91.

184. Rasch S, Phillip V, Reichel S, et al. Open surgical versus minimal invasive necrosectomy of the pancreas-a retrospective multicenter analysis of the German Pancreatitis Study Group. PLoS One 2016;11:e0163651.

185. Martin RF, Hein AR. Operative management of acute pancreatitis. Surg Clin North Am 2013;93:595-610. 